\title{
Leukocyte Antigen-Related Protein Tyrosine Phosphatase Receptor: A Small Ectodomain Isoform Functions as a Homophilic Ligand and Promotes Neurite Outgrowth
}

\author{
Tao Yang, ${ }^{1}$ Ramon Bernabeu, ${ }^{2}$ Youmei Xie, ${ }^{1}$ Julie S. Zhang, ${ }^{2}$ Stephen M. Massa, ${ }^{2}$ Hans C. Rempel, ${ }^{3}$ and Frank M. Longo ${ }^{1}$ \\ ${ }^{1}$ Department of Neurology, University of North Carolina at Chapel Hill, Chapel Hill, North Carolina 27599, and Departments of ${ }^{2}$ Neurology and ${ }^{3}$ Laboratory \\ Medicine, University of California, San Francisco/Veterans Affairs Medical Center, San Francisco, California 94121
}

The identities of ligands interacting with protein tyrosine phosphatase (PTP) receptors to regulate neurite outgrowth remain mainly unknown. Analysis of cDNA and genomic clones encoding the rat leukocyte common antigen-related (LAR) PTP receptor predicted a small, $\sim 11 \mathrm{kDa}$ ectodomain isoform, designated LARFN5C, containing a novel $\mathrm{N}$ terminal followed by a C-terminal segment of the LAR fifth fibronectin type III domain. RT-PCR and Northern blot analysis confirmed the presence of LARFN5C transcripts in brain. Transfection of COS cells with LARFN5C-Fc cDNA resulted in expression of the predicted protein, and Western blot analysis verified expression of $\sim 11 \mathrm{kDa}$ LARFN5C protein in vivo and its developmental regulation. Beads coated with rLARFN5C demonstrated aggregation consistent with homophilic binding, and pull-down and immunoprecipitation assays demonstrated that rLARFN5C associates with the LAR receptor. rLARFN5C binding to COS cells was dependent on LAR expression, and rLARFN5C binding to LAR + / hippocampal neurons was fivefold greater than that found by using LAR-deficient $(-/-)$ neurons. Substratum-bound rLARFN5C had potent neuritepromoting effects on LAR $+/+$ neurons, with a fivefold loss in potency with the use of LAR - / - neurons. rLARFN5C in solution at low nanomolar concentrations inhibited neurite outgrowth induced by substratum-bound rLARFN5C, consistent with receptor-based function. These studies suggest that a small ectodomain isoform of a PTP receptor can function as a ligand for the same receptor to promote neurite outgrowth.

Key words: LAR; protein tyrosine phosphatase; neurite outgrowth; homophilic binding; cell adhesion molecule; fibronectin type III repeat

\section{Introduction}

Considerable evidence demonstrates that protein tyrosine phosphatase (PTP) receptors are important regulators of neurite outgrowth (Van Vactor, 1998; Chisholm and Tessier-Lavigne, 1999; den Hertog, 1999; Bixby, 2000; Petrone and Sap, 2000; Stoker, 2001). Drosophila null mutant analyses suggest that the Drosophila leukocyte common antigen-related (Dlar) PTP receptor regulates neurite pathfinding during development (Krueger et al., 1996; Desai et al., 1997). Null mutant crosses indicate that Dlar modulates intracellular signaling mechanisms involving Robo and DCC and that the opposing actions of Dlar and the Abelson (Abl) tyrosine kinase control the phosphorylation state of the Enabled (Ena) protein, a regulator of axonal actin assembly (Wills et al., 1999; Bashaw et al., 2000; Lanier and Gertler, 2000). Dlar functions in synaptic target recognition of Drosophila retinal neurons (Clandinin et al., 2001; Maurel-Zaffran et al., 2001) and interacts with liprin- $\alpha$ to control synapse morphogenesis (Kaufmann et al., 2002). In leech neural development the inhibition of HmLAR2 (an ortholog of Dlar) function leads to shortened and

Received Sept. 11, 2002; revised Jan. 30, 2003; accepted Feb. 6, 2003.

This work was supported by National Institutes of Health Grant R01 AG09873. We thank Dr. Q. Yu for providing full-length LAR cDNA and Dr. Marc Tessier-Lavigne at University of California, San Francisco for helpful discussions regarding novel ligand-receptor mechanisms regulating neurite outgrowth. We also thank Weining Yin for outstanding technical assistance.

Correspondence should be addressed to Dr. Frank M. Longo, University of North Carolina School of Medicine, Department of Neurology CB7025, University of North Carolina at Chapel Hill, Chapel Hill, NC 27599. E-mail: longof@glial.med.unc.edu.

Copyright $\odot 2003$ Society for Neuroscience $\quad 0270-6474 / 03 / 233353-11 \$ 15.00 / 0$ aberrant neuronal projections, navigational crossover errors, and growth cone collapse (Gershon et al., 1998; Baker and Macagno, 2000; Baker et al., 2000).

The mammalian leukocyte antigen-related (LAR) PTP receptor also plays an important role in regulating neurite outgrowth. LAR mRNA is expressed in neurons (Longo et al., 1993; Schaapveld et al., 1998), LAR protein is present along neurites and in growth cones (Zhang et al., 1998), and LAR alternative splicing is coordinated in a spatiotemporal manner during development (Zhang and Longo, 1995). Studies in LAR-deficient transgenic mice have demonstrated decreased cholinergic fiber innervation of the hippocampal dentate gyrus (Yeo et al., 1997; Van Lieshout et al., 2000) and markedly impaired post-injury sciatic nerve regeneration (Xie et al., 2001).

Key steps in elucidating PTP mechanisms modulating neurite outgrowth will be the identification of ligands interacting with PTP receptors and the identification of subdomains mediating such interactions. In some cases neurite outgrowth might be regulated via PTP homophilic interactions. Recombinant proteins corresponding to full-length ectodomains of РТР $\kappa, \mathrm{PTP} \mu$, and PTP $\delta$ exhibit homophilic binding, and their addition to cultured neurons promotes neurite outgrowth (Bixby, 2000). Whether this neurite-promoting activity is mediated via homophilic interactions or heterophilic interactions with heretofore-unidentified receptors remains unknown. In addition, the specific PTP extracellular subdomains regulating neurite outgrowth remain to be identified.

We postulated that patterns of LAR ectodomain alternative 
splicing might provide useful clues for the identification of ectodomain segments likely to be involved in ligand-receptor interactions. A retained intron present between the fifth and sixth fibronectin type III (FNIII) domains of LAR introduces an inframe stop codon predicting a truncated ectodomain isoform (Zhang and Longo, 1995). We hypothesized that a truncated LAR ectodomain isoform might exist that undergoes homophilic binding and promotes neurite outgrowth. Support of this hypothesis would indicate that LAR and perhaps other LAR-type PTPs modulate neurite outgrowth via homophilic interactions. Moreover, such studies would provide the first demonstration of a PTP receptor subdomain capable of homophilic binding and mediation of neurite outgrowth.

\section{Materials and Methods}

Isolation of genomic DNA and $m R N A$. Genomic DNA was isolated from whole brain harvested from Sprague Dawley rats at the ages 2-3 months via standard protocols. Rat brain poly(A) RNA was purchased from Clontech (Palo Alto, CA). This poly(A) RNA was isolated by a modified guanidinium thiocyanate method, followed by poly(A) RNA selection that used at least three rounds of oligo-dT/cellulose purification. Poly(A) RNA from mouse hippocampus was isolated with the Fast-Track kit (Invitrogen, San Diego, CA).

Generation of clones containing the LASE-d Insert. Rapid amplification of cDNA ends (RACE; Clontech) combined with nested PCR was used to isolate cDNAs containing the LAR LASE-d insert. First-strand cDNA product was derived by using $5 \mu \mathrm{g}$ of rat brain poly(A) RNA, and adapters were ligated to both ends. First-round PCR was conducted by using the AP1 adaptor upstream primer and a downstream primer corresponding to the $75 \mathrm{bp}$ LASE-d insert (LASE-dA, 5' -CCT GCT GCC CAC CCA GCT TAG TCC CTG ACC CCT CAC TCA C-3'). Second-round PCR was conducted by using the nested AP2 upstream adapter primer and a nested downstream primer corresponding to a further upstream part of the LASE-d insert (LASE-dB, 5' -CTG AAC AGC ACG CAC TGG GCT CTG GTG CCG CCC TCC CTG C-3'). PCR was performed with annealing temperature at $72^{\circ} \mathrm{C}$ for 5 cycles each and at $68^{\circ} \mathrm{C}$ for 25 cycles. PCR products were subcloned into the pCRII vector for DNA sequencing.

RT-PCR protocols were conducted as described previously (Zhang and Longo, 1995). Transcripts containing the LASE-e and LASE-d retained introns were detected by using an upstream primer corresponding to a 5' site of the LASE-e intron (5' -TGT CTC AGC TGA GAG CAG GAT GGG TA-3') and a downstream primer corresponding to the LASE-d retained intron (primer LASE-dA as listed above).

Northern blot analysis. Northern blot hybridization was performed with the protocol described in the RNA detector Northern blotting kit (KPL, Gaithersburg, MD). Poly(A) RNA (4 $\mu \mathrm{g}$ ) was electrophoresed through a $1 \%$ agarose-formaldehyde gel and transferred to Hybond nylon membranes (Amersham Biosciences, Arlington Heights, IL). Biotinlabeled probes (with a specific activity of $50 \mathrm{ng} / \mathrm{ml}$ ) were made with T7 RNA polymerase synthesized with the MAXIscript in vitro transcription kit (Ambion, Austin, TX) by using PCR-derived, T7 promotercontaining DNA templates corresponding to either the novel $\mathrm{N}$ terminal or the LAR portion of LARFN5C.

Generation of LARFN5C antibody. LARFN5C rabbit antiserum was produced by AnaSpec (San Jose, CA) with standard procedures. Rabbits were injected with a purified synthetic peptide corresponding to residues 29-48 in the novel N terminal present in LARFN5C. Antibody (designated as LARFN5C 29-48 antibody) was purified by immunoaffinity purification with the corresponding peptide.

Immunoprecipitation and Western blot analysis. Tissues were homogenized in the following lysis buffer: $20 \mathrm{~mm}$ Tris, $\mathrm{pH}$ 8.0, $137 \mathrm{~mm} \mathrm{NaCl}, 1 \%$ NP-40, 10\% glycerol, $1 \mathrm{~mm}$ PMSF, $10 \mu \mathrm{g} / \mathrm{ml}$ aprotinin, and $1 \mu \mathrm{g} / \mathrm{ml}$ leupeptin. Lysates were centrifuged at $14,000 \times g$ for $10 \mathrm{~min}$, supernatant was collected, and protein concentrations were determined by the BCA protein assay reagent (Pierce, Rockford, IL). Immunoprecipitations were performed by adding LARFN5C 29-48 or LASE-c antibody (raised against the nine amino acid LASE-c insert) (Zhang et al., 1998) and incubating with $50 \mu \mathrm{l}$ of protein $\mathrm{A} / \mathrm{G}$ agarose. Immunocomplexes were centrifuged for $1 \mathrm{~min}$ at $14,000 \times \mathrm{g}$, washed three times in lysis buffer, eluted with $50 \mu \mathrm{l}$ of $2 \times$ protein sample buffer, and boiled for $5 \mathrm{~min} ; 25 \mu \mathrm{l}$ was loaded per lane for electrophoresis. For immunoblots the samples were electrophoresed through a NuPAGE 4-12\% Bis-Tris Gel with MES (2-[N-morpholino] ethanesulfonic acid) SDS running buffer (Invitrogen) and transferred to polyvinylidene difluoride membranes. Western blot signals were detected by the ECL chemiluminescence system (Amersham Biosciences). To control for variations in protein loading, we stripped and reprobed the blots with $\beta$-actin monoclonal antibody (Sigma, St. Louis, MO).

Pull-down assays. Pull-down assays were conducted as previously described (Wills et al., 1999; Bashaw et al., 2000). Protein lysates of embryonic day 16 (E16) hippocampal tissues prepared as described above were incubated for $1 \mathrm{hr}$ with His-tagged fusion protein followed by pull down with TALON resin pellets (Clontech). As a control for protein binding specificity, lysates were incubated with resin pellets coated with Positope control protein (Invitrogen) containing the following epitope tags: Xpress, c-myc, V5, polyHis, HisG, thioredoxin, and green fluorescent protein. Bound resin pellets were washed three times with lysis buffer. Eluted proteins were assessed with the Western blot protocol described above.

Production, purification, and characterization of recombinant LARFN5C. The pLARFN5C cDNA clone was amplified by RT-PCR, using rat brain mRNA, a sense primer corresponding to a region $9 \mathrm{bp}$ upstream of the putative ATG translation start codon, and an antisense primer corresponding to a site within the LASE-d insert $37 \mathrm{bp}$ downstream from the LASE-d stop codon. The sense primer contained an added EcoRI site (5'-GG GAA TTC TGC TCA GTG ATG CAG GGA CTT G-3'), and the antisense primer contained an added HindIII site ( $5^{\prime}$-CC CTC AAG CTT GCT GCC CAC CCA GCT TAG TCC CTG ACC CCT CAC TCA C-3'). The amplified fragment was digested with EcoRI and HindIII and ligated into the pBlueBacHis.2B vector (Invitrogen). The sequence of the resulting expression construct was confirmed via automated DNA sequencing (Seqwright, Houston, TX). The pBlueBacHis.2B-LARFN5C expression construct was used to transfect Sf9 insect cells via a standard recombinant protein expression protocol (Invitrogen). The His-tagged recombinant protein, termed rLARFN5C, was purified with the TALON Superflow Metal Affinity Resin Purification System (Clontech).

To synthesize a cDNA construct expressing a chimeric LARFN5C-Fc protein, we amplified a PCR product corresponding to full-length LARFN5C by using a $5^{\prime}$ primer containing a BamHI restriction site and a 3' primer containing SpeI. The BamHI/SpeI-digested fragment of the PCR product was ligated into the Fc-containing pGEM7 vector. A Bam HI/XhoI-digested $1.0 \mathrm{~kb}$ fragment (LARFN5C-Fc) was cloned into the pcDNA3.1 expression vector (Invitrogen). Sequence and reading frame were verified by automated DNA sequencing (Seqwright).

Microsphere aggregation assays. Fluorescently labeled microspheres $(\sim 1.75 \mu \mathrm{m}$ in diameter; Polysciences, Warrington, PA) were incubated in $300 \mu \mathrm{g} / \mathrm{ml}$ solutions of either rLARFN5C or bovine serum albumin (BSA) in PBS overnight at room temperature. Microspheres were blocked with $0.25 \mathrm{M}$ ethanolamine for $30 \mathrm{~min}$ at room temperature and then with $10 \mathrm{mg} / \mathrm{ml} \mathrm{BSA}$ in PBS for an additional $30 \mathrm{~min}$. After blocking, the microspheres were washed three times with PBS, suspended in $50 \mu \mathrm{l}$ of PBS, sonicated, and then incubated in 96-well plates at room temperature for $1 \mathrm{hr}$ on a rotary shaker. For antibody inhibition experiments the antibody was added to the $50 \mu \mathrm{l}$ incubation solution to a final concentration of $10 \mu \mathrm{g} / \mathrm{ml}$. Then $10 \mu \mathrm{l}$ aliquots were removed and examined on microscope slides under a fluorescence microscope at a wavelength of $590 \mathrm{~nm}$.

Experimental animals. LAR-deficient (LAR -/-) transgenic mice have been described previously (Skarnes et al., 1995; Yeo et al., 1997; Xie et al., 2001). A transgene located near the $\mathrm{N}$-terminal encoding region of the LAR gene and containing a splice acceptor linked with a cassette encoding $\beta$-geo creates a "gene trap" resulting in highly truncated LAR transcripts encoding only a part of the $\mathrm{N}$-terminal Ig region, followed by the $\beta$-geo protein. Thus in most transcripts almost the entire ectodomain, along with the entire catalytic endodomain, is absent. Long-range splicing skipping the transgene insert results in trace expression of $\sim 8$ 
and $\sim 7 \mathrm{~kb}$ LAR transcripts. Expression of an $\sim 6 \mathrm{~kb}$ LAR transcript (possibly regulated via a second, further downstream, promoter) occurs at similar levels in LAR $+/+$ and $-/-$ mice. $\mathrm{LAR}+/+$ and LAR $-/-$ littermates were derived via heterozygous crosses.

Cell culture. COS-7 cells were maintained in DMEM containing 10\% fetal bovine serum (FBS) and incubated at $37^{\circ} \mathrm{C}$ with $5 \% \mathrm{CO}_{2}$. Dissociated hippocampal neurons were obtained from E18 LAR +/+ and LAR - / - mice hippocampi via established protocols (Goslin et al., 1998) and maintained in DMEM/F12 medium supplemented with 10\% FBS. Neurons from $\mathrm{LAR}+/+$ and $\mathrm{LAR}-/-$ mice were cultured in fourchamber slides coated with $10 \mu \mathrm{g} / \mathrm{ml}$ poly-L-lysine for $24 \mathrm{hr}$. For binding experiments the COS cells or neurons were incubated with rLARFN5C at the indicated concentrations for $3 \mathrm{hr}$ at $37^{\circ} \mathrm{C}$ with $5 \% \mathrm{CO}_{2}$. Cells were rinsed twice with PBS, fixed with $4 \%$ paraformaldehyde (PFA) for 20 min, and then washed twice with PBS.

Transfection of COS-7 cells. COS-7 cells were plated at low (for immunostaining) or high (for protein expression assays) density overnight. Lipofectamine ( $60 \mu \mathrm{l}$; Invitrogen) was preincubated with $3.0 \mu \mathrm{g}$ of cDNA (for LAR) or $4.0 \mu \mathrm{g}$ of cDNA (for LARFN5C-Fc) in $1 \mathrm{ml}$ of DMEM transfection medium at room temperature for $15 \mathrm{~min}$. cDNA consisted of the pBabe vector or pcDNA3.1 vector without insert (null) or containing full-length LAR (Weng et al., 1998) or full-length LARFN5C-Fc. The volume of the transfection solution was brought up to $6 \mathrm{ml}$ and layered over cells for $3 \mathrm{hr}$ at $37^{\circ} \mathrm{C}$. After transfection the LAR-expressing cells prepared for immunostaining were incubated in DMEM containing 10\% FBS and then fixed at $24 \mathrm{hr}$. LARFN5C-Fc-expressing cells were incubated in a T-75 flask in a volume of $12 \mathrm{ml}$ virus production serum-free medium (VP-SFM) with $10 \mathrm{ng} / \mathrm{ml}$ epidermal growth factor (EGF). At 48 hr the culture medium was collected without disruption of the attached cell monolayer and then centrifuged to ensure the removal of any floating cells. Culture medium $(2 \mathrm{ml})$ was lyophilized and then resuspended in $170 \mu \mathrm{l}$ of protein lysis buffer. LARFN5C-Fc-transfected cells were harvested from the T-75 flask via the addition of lysis buffer and processed for subsequent Western blot analysis. The chimeric LARFN5C-Fc protein was detected by using peroxidase-conjugated AffiniPure goat antimouse IgG Fc fragment-specific antibody (Jackson ImmunoResearch, West Grove, PA).

Immunofluorescent staining and quantification. Fixed COS cells or hippocampal neurons were blocked in 3\% normal serum and 1\% BSA in PBS for $2 \mathrm{hr}$. Then they were incubated for $36 \mathrm{hr}$ at $4^{\circ} \mathrm{C}$ in a mixture containing antibodies directed against the LAR $\mathrm{N}$ terminal (monoclonal antibody, 1:800; BD Transduction Laboratories, Franklin Lakes, NJ) and $0.1 \mu \mathrm{g} / \mathrm{ml}$ LARFN5C 29-48 rabbit polyclonal antibody. Secondary antibodies consisting of $\mathrm{Cy} 3$ red-conjugated donkey anti-mouse (Jackson ImmunoResearch) and Alexa 488 green-conjugated goat anti-rabbit IgG (1:250; Molecular Probes, Eugene, OR) were applied for $2 \mathrm{hr}$ at room temperature in the dark. Fluorescent signal was detected with a confocal microscope (Leica Laser Confocal TCS SP) through a $40 \times$ oil immersion lens. For GAP-43 immunostaining the cells were treated after fixation with $0.1 \%$ Triton $\mathrm{X}-100$ for $10 \mathrm{~min}$ at room temperature and then incubated with GAP-43 rabbit polyclonal antibody (1:400; Chemicon, Temecula, CA). Secondary antibody consisted of Alexa 488 greenconjugated goat anti-rabbit IgG (Molecular Probes).

Quantification of fluorescent staining was performed with the NIH Image program. For COS cells the fluorescent density measurements were made in five randomly selected $30 \times 30$ pixel fields per cell. Under each condition 15 cells were selected randomly for assessment, generating a total of 75 measurements. For neurons the measurements were made in three randomly selected $15 \times 15$ pixel fields per cell. Under each condition 10 cells were selected randomly for assessment, generating a total of 30 measurements.

Cell attachment and neurite outgrowth assays. Six-well plates were coated with nitrocellulose $\left(0.5 \mathrm{~cm}^{2} / \mathrm{ml}\right)$ (Wang and Bixby, 1999). Test proteins were prepared in PBS solutions and applied as $5 \mu$ ldroplets to a designated midpoint in each well, followed by incubation for $1 \mathrm{hr}$ at $37^{\circ} \mathrm{C}$. Remaining substratum binding sites were blocked with $1 \% \mathrm{BSA}$ in PBS for $1 \mathrm{hr}$. As negative control, aliquots of rLARFN5C were subjected to immunoprecipitation with His tag or LASE-c antibody. Dissociated E18 hippocampal neurons were plated in culture media at a density of
$1 \times 10^{5}$ to $1 \times 10^{6}$ cells per well. After $2 \mathrm{hr}$ the wells were washed three times with PBS and fixed with $2.5 \%$ glutaraldehyde. The number of substrate-attached cells per field was counted in each of 10-15 fields per well. Fields were selected systematically by counting parallel rows of adjacent fields. For neurite outgrowth assays E18 hippocampal neurons were cultured for $24 \mathrm{hr}$. After fixation systematically selected adjacent fields in parallel rows were photographed. In a blinded manner the neurite length for each neurite longer than one cell body diameter was measured.

\section{Results}

LAR alternative splicing predicts a novel LAR protein isoform A rat cDNA clone ( $\mathrm{pLARFN5C)}$ ) was obtained in which the $75 \mathrm{bp}$ LASE-d insert was followed upstream by the exon encoding the C-terminal half of the LAR FNIII-5 domain and the exon encoding the 27 bp LASE-c insert (Fig. 1A,D). Upstream from the LASE-c exon was $\sim 350$ bp of novel sequence likely representing a retained intron. This retained intron was termed LASE-e (LAR alternatively expressed element-e). The open reading frame (ORF) created by the furthest downstream ATG potential start codon present in the LASE-e insert extending to the furthest upstream stop codon present in the LASE-d insert predicted an $\sim 11 \mathrm{kDa}$ isoform termed LARFN5C. The LARFN5C sequence predicted a protein with a novel $\mathrm{N}$ terminal containing 49 residues not present in constitutive LAR, followed by the nine residue LASE-c insert, the 37 residue $\mathrm{C}$ terminus half of the FNIII-5 domain, and four residues present before the LASE-d in-frame stop codon (Fig. 1B). Analysis of the predicted LARFN5C sequence for signal peptide motifs that used the combined neural network approach described by Nielsen et al. (1997) demonstrated potential cleavage sites at residues $14(Y$ score $=0.17)$ and 35 ( $Y$ score $=0.27$; the higher $Y$ score indicates the most likely cleavage site). The $S$ score average over residues $1-14$ was 0.56 (values $>0.5$ are consistent with a segment constituting a signal peptide) and over residues $1-35$ was 0.38 . Thus sequence analysis raised the possibility of a secretory signal at the LARFN5C N terminal although the more typical pattern for known secreted proteins of the $S$ score averaging $>0.5$ over the most likely predicted cleaved fragment was not present.

To characterize the LASE-e retained intron on the genomic level, we derived a rat genomic DNA clone by using a downstream primer corresponding to LASE-c and an upstream primer corresponding to a site within the N-terminal portion of the FNIII-5 domain. The resulting $\sim 2.7 \mathrm{~kb}$ PCR product was subcloned into the pCRII vector and sequenced. Sequence analysis demonstrated that the LASE-e intron was $\sim 2.7 \mathrm{~kb}$ in length and directly linked the exons encoding the $\mathrm{N}$-terminal half of the FNIII-5 domain and the exon encoding LASE-c (Fig. 1C,D). Downstream of the LASE-c exon an intron of $\sim 1.3 \mathrm{~kb}$ in length was identified via PCR amplification of genomic DNA by using an upstream primer corresponding to the LASE-c exon and a downstream primer corresponding to the FNIII-5 C-terminal exon (Fig. 1C,D).

\section{LARFN5C isoform transcripts and protein are present in vivo, and protein levels are regulated developmentally}

The presence of mRNA encoding LARFN5C (transcripts containing the LASE-e and LASE-d retained introns) was assessed in poly(A) mRNA extracted from rat brain by RT-PCR. LARFN5C transcripts were detected by using primers corresponding to sites within LASE-e and LASE-d and generating an expected $534 \mathrm{bp}$ product. LARFN5C transcripts were present in adult brain and embryonic hippocampus (Fig. 2A). Using a riboprobe corresponding to the 150 nucleotides encoding the novel $\mathrm{N}$ terminal of 
LARFN5C, we identified an $\sim 1.6 \mathrm{~kb}$ transcript in hippocampal tissue (Fig. 2 B). Using a riboprobe corresponding to the 147 nucleotides encoding the LASE-c and FNIII-5 regions of LARFN5C, we detected $\sim 8 \mathrm{~kb}$ (the size expected for LAR) and $\sim 1.6 \mathrm{~kb}$ transcripts (Fig. $2 B$ ). Detection of the $\sim 1.6 \mathrm{~kb}$ transcript by both the novel $\mathrm{N}$ terminal and LAR probes was consistent with the previous CDNA and RT-PCR results suggesting a novel alternatively spliced LAR transcript containing the region encoding the novel $\mathrm{N}$ terminal. The relative levels of LARFN5C and LAR transcripts were similar, with a slightly increased ratio of LARFN5C to LAR in postnatal day 21 (P21) as compared with adult hippocampus (Fig. 2C).

For protein expression studies mouse tissues were used to take advantage of the availability of LAR-deficient transgenic mice as described below. Western blot analysis of mouse E16 hippocampal tissue extracts that used LARFN5C 29-48 antibody directed against residues present in its $\mathrm{N}$ terminus and absent in LAR demonstrated an $\sim 11 \mathrm{kDa}$ signal consistent with that predicted for LARFN5C (Fig. 2D). A band between the 38 and $49 \mathrm{kDa}$ markers was detected also. As predicted by the presence of the LASE-c insert within LARFN5C, analysis with LASE-c antibody also detected an $\sim 11 \mathrm{kDa}$ band. LASE-c antibody also detected a band at $\sim 22 \mathrm{kDa}$ and two bands between the 38 and $49 \mathrm{kDa}$ markers. Incubation of blots in the absence of primary antibody, with preimmune serum, or with LARFN5C 29-48 antibody preincubated with LARFN5C 29-48 peptide resulted in loss of signal (Fig. 2D). To confirm further the presence of LARFN5C protein in tissue extract, we performed a series of reciprocal immunoprecipitations with LARFN5C 29-48 and LASE-c antibodies. Western blot analysis that used LARFN5C $29-48$ antibody detected $\sim 11$ and $\sim 44 \mathrm{kDa}$ species in immunoprecipitates formed with both LARFN5C and LASE-c antibodies (Fig. 2E). In reciprocal studies Western blot analysis that used LASE-c antibody detected $\sim 11$ and $\sim 44 \mathrm{kDa}$ species in immunoprecipitates formed with LARFN5C 29-48 and LASE-c antibodies. No $\sim 11$ and $\sim 44 \mathrm{kDa}$ signals were detected in immunoprecipitates formed with preimmune sera. Together, Western blot analyses along with reciprocal immunoprecipitations confirm the presence of LARFN5C protein in hippocampal tissue extracts. The persistent detection of the $\sim 44 \mathrm{kDa}$ band in immunoprecipitates along with Western analyses raised the possibility of the presence of LARFN5C in a tetrameric state (assessed below).

Similar levels of LARFN5C protein were present in hippocampal tissues and E18 cultured hippocampal cells obtained from LAR $+/+$ and $-/-$ mice, consistent with previous studies (Yeo et al., 1997) showing that expression of truncated LAR transcripts is not reduced in LAR $-/-$ mice (Fig. $2 F$ ). In LAR $+/+$ mice the

$\mathrm{D}$

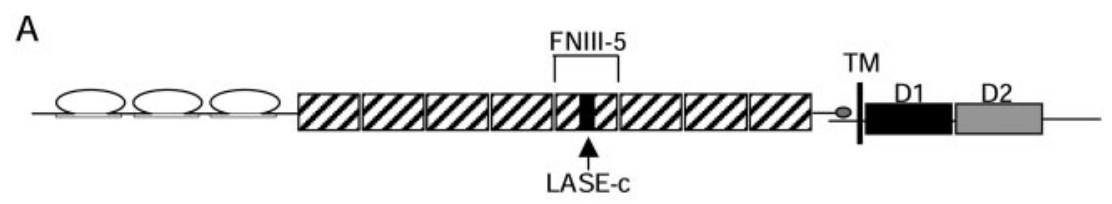

B $\quad \sim 11 \mathrm{kDa}$

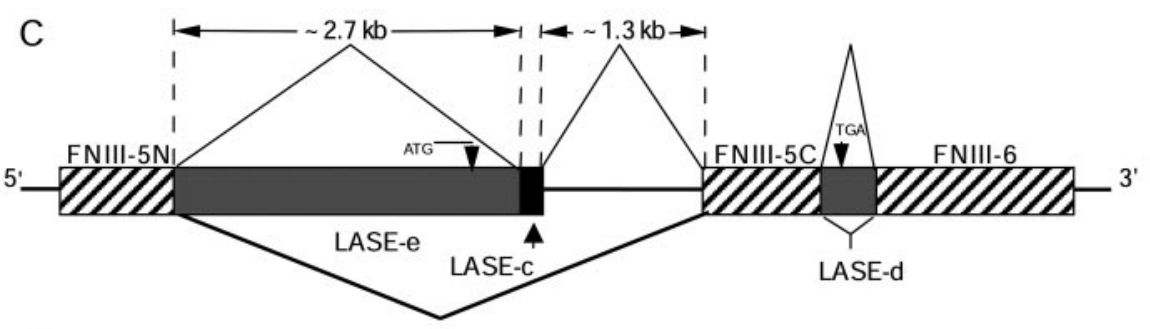
TAT GTG COG CTG GAG AAT GGG GAG COC OGA GGC CAG CCC ATC ATC CAG GAT GTC ATG CTG GCT GAG GCT CAG
$\mathrm{Y}$ tgt cgt gga cag tgc tgg gtg gca ggg taa--.----ggt cac tca gct cag gca act cta att tag tgt ctc agc tga gag cag gat ggg tag aca gac aga cag agc tga aca gcc ata gca gga cat tgg gac tcc agg tat ata gca gga tat ata gtc atc cct tag tgt ctt ccc tct gcc tga gct gtc aag tct gtc ttc ata tct gac agt cca cca tgt ctc cet gcc ctc gac agg $\propto$ t ggc aca cac agt cgg tgc tca gtg atg cag gga ctt gtg tct gag tgg gga

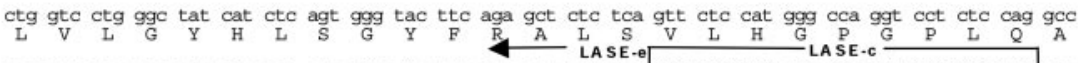

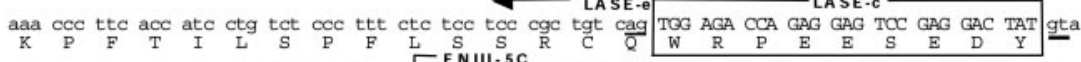

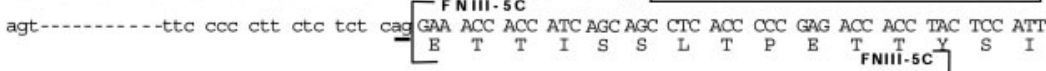

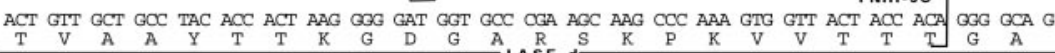
$\frac{\text { at }}{G}{ }_{\mathrm{E}}$ tga ggg gtc agg gac taa gct ggg tgg gca gca ggg agg gog gca cca gag ccc agt gog tgc tgt tca $g$

Figure 1. Genomic organization and alternative splicing predicting the LARFN5C isoform. A, Full-length LAR contains three lgG immediately upstream of the exon encoding LASE-c and the LASE-d retained intron immediately down作 residue N terminal followed by the LASE-C and FNIII-5C domains. Constitutive LAR transcript splicing is indicated by the bottom thicker splice indicator line, and alternative splicing is shown by the top thinner lines. D, Genomic sequence demonstrates the splice donor (gt underlined) and splice acceptor (ag underlined) sites of the $\sim 2.7 \mathrm{~kb}$ LASE-e retained intron and the $\sim 1.3 \mathrm{~kb}$ LARFN5C novel exonic sequence is shown in lower case letters with amino acid translation; stop codons are boxed. Antibody LARFN5C 29 - 48 was raised against a synthetic peptide corresponding to N-terminal residues PGPLQAKPFTILSPFLSSRC.

LARFN5C levels were highest in E16 hippocampal tissue and decreased during development. Interestingly, Western blot analysis of cell as well as tissue extracts demonstrated an $\sim 44 \mathrm{kDa}$ band along with the expected $\sim 11 \mathrm{kDa}$ band. Quantitation of the $\sim 11 \mathrm{kDa}$ signal showed a 17 -fold reduction in LARFN5C levels during development (Fig. 2G). Similar developmental regulation of the $\sim 11 \mathrm{kDa}$ LARFN5C protein also was demonstrated in cortex and spinal cord tissue (data not shown).

\section{Expression and purification of recombinant LARFN5C}

An EcoRI-HindIII restriction enzyme fragment of the pLARFN5C insert was cloned into the pBlueBacHis.2B vector for expression in Sf9 cells. The expected product consisted of an $\sim 16 \mathrm{kDa}$ protein containing a His tag, followed by 45 vector-based residues containing an enterokinase cleavage site and the 99 LARFN5C residues encoded by pLARFN5C. His tag-based purification from Sf 9 cell preparations yielded the expected $\sim 16 \mathrm{kDa}$ protein as detected by GelCode Blue staining of SDS-PAGE gels (Fig. 3A). A 
A
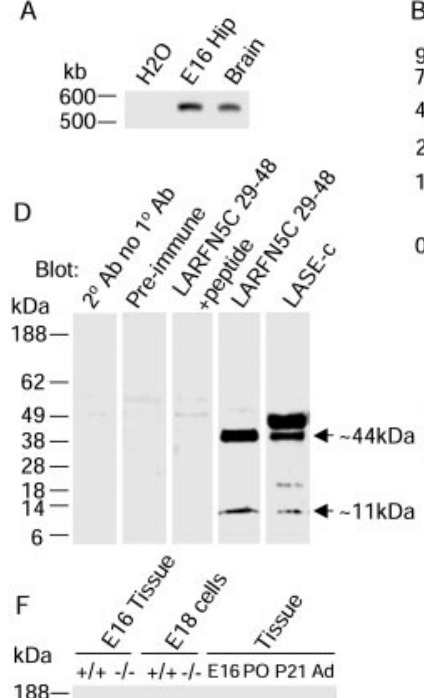

$188-$

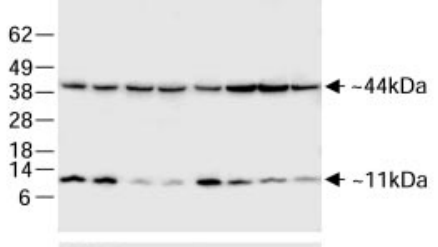

$----1-$
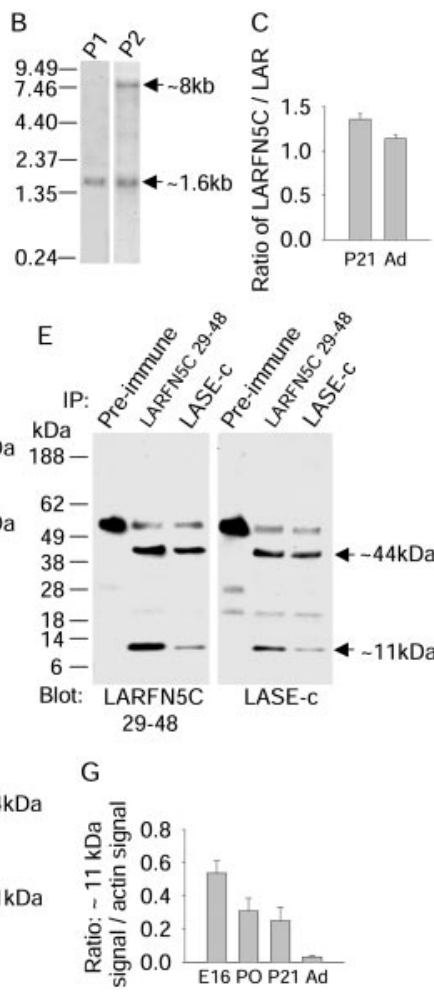

Figure 2. RT-PCR, Northern blot, and Western blot analysis of LARFN5C expression. A, RTPCR analysis was performed by using an upstream primer corresponding to a site within LASE-e and a downstream primer corresponding to a site within LASE- $d$ generating a predicted product of $534 \mathrm{bp}$. Poly(A) mRNA ( $0.05 \mu \mathrm{g} /$ reaction) from rat whole brain and rat E16 hippocampus was assessed. $\mathrm{H}_{2} \mathrm{O}$ served as a negative control. $B$, Northern blot analysis of $\mathrm{P} 21$ hippocampal poly (A) RNA was conducted by using a riboprobe corresponding to the 150 nucleotides encoding the novel N terminal of LARFN5C (P1) or corresponding to the 147 nucleotides encoding the LASE-C and FNIII-5 regions of LARFN5C (P2). P1 detected an $\sim 1.6 \mathrm{~kb}$ transcript, and P2 detected an $\sim 1.6 \mathrm{~kb}$ transcript of identical size as well as the expected LAR $\sim 8 \mathrm{~kb}$ transcript. $C$, Northern blot autoradiograms derived by using the $\mathrm{P} 2$ probe and RNA isolated from $\mathrm{P} 21$ and adult (Ad) hippocampus were assessed by scanning densitometry; the ratio of LARFN5C $(\sim 1.6 \mathrm{~kb})$ over the LAR ( $\sim 8 \mathrm{~kb}$ ) signal was calculated (mean $\pm \mathrm{SE} ; n=6$ blots). A small but significant decrease in this ratio was detected in the adult when compared with the P21 samples ( $p<$ 0.05 , Mann-Whitney). $D$, Protein extract $(40 \mu \mathrm{g})$ from E16 mouse hippocampal tissue was applied to each lane. Blots were incubated with the indicated antibodies. Negative controls included omission of primary antibody, use of preimmune antiserum, and preincubation of primary antibody with LARFN5C $29-48$ peptide. LARFN5C 29-48 and LASE-c antibodies detected an $\sim 11 \mathrm{kDa}$ protein (bottom arrow) consistent with the predicted size of LARFN5C. Both antibodies also detected an $\sim 44 \mathrm{kDa}$ signal (top arrow). E, E16 hippocampal tissue extracts were immunoprecipitated (IP) with preimmune, anti-LARFN5C 29-48, or LASE-c antibodies. Western blot analysis of IPs with anti-LARFN5C $29-48$ or LASE-c antibodies detected $\sim 11$ and $\sim 44 \mathrm{kDa}$ proteins. F, Protein extract (40 $\mu \mathrm{g}$ ) was applied to each lane at the indicated developmental time points from E16 hippocampal tissue and E18 cultured hippocampal neurons derived from $L A R+/+$ and $-/-$ mice and hippocampal tissues. Blots were incubated with LARFN5C 29-48 antibody followed by reprobing with actin antibody (bottom panel). Similar levels of LARFN5C were present in tissue and cells derived from LAR $+/+$ and $-/-$ mice. $G$, Western blot autoradiograms derived by using LARFN5C 29-48 antibody were assessed by scanning densitometry. The ratio of LARFN5C signal over the actin signal demonstrated that LARFN5C protein levels in the hippocampus decreased significantly during development by $94 \%$ (mean ratios $\pm \mathrm{SE} ; p<0.05 ; n=4 ; \mathrm{ANOVA}$ ).

faint band at $\sim 64 \mathrm{kDa}$ was also present. Higher-resolution Western blots that used the LASE-c antibody revealed bands at $\sim 16$, $\sim 32$, and $\sim 64 \mathrm{kDa}$ (Fig. $3 A$ ). The detection of the $\sim 32$ and $\sim 64$ $\mathrm{kDa}$ bands suggested the possibility of LARFN5C homophilic binding resulting in the presence of rLARFN5C dimeric and tetrameric complexes. Enterokinase cleavage of rLARFN5C yielded the expected $\sim 11 \mathrm{kDa}$ protein species detected by GelCode Blue

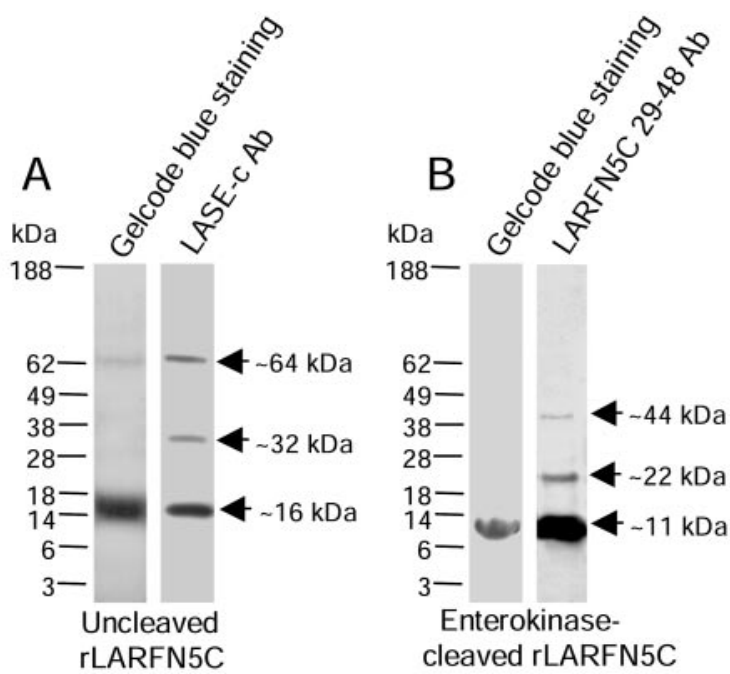

C

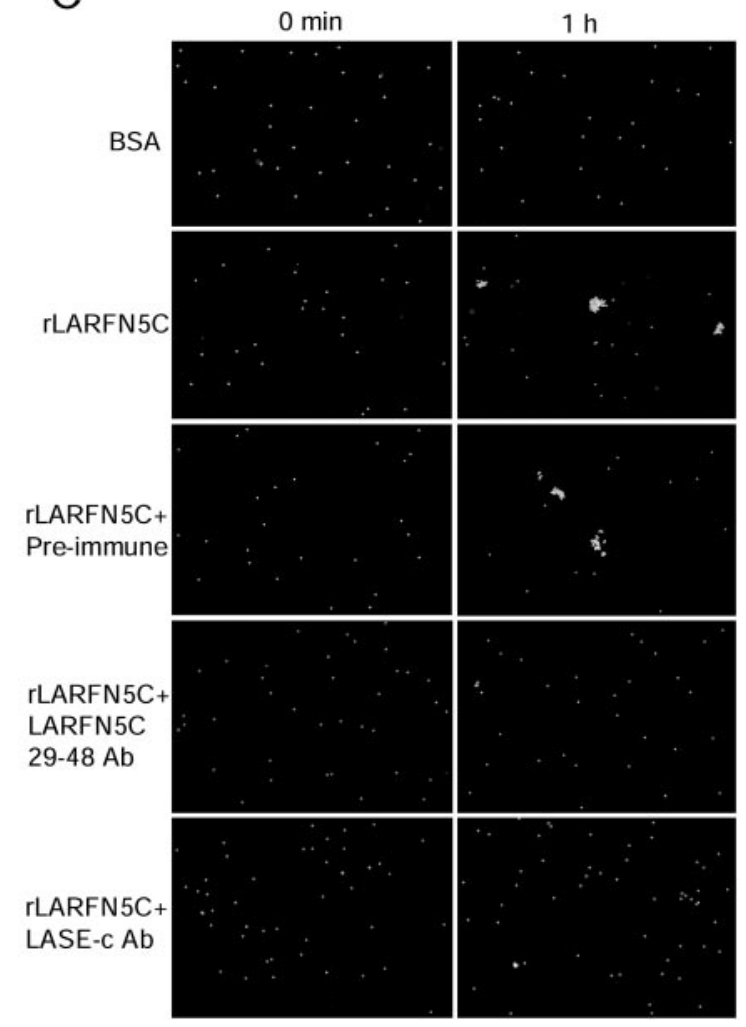

Figure 3. Purification of rLARFN5C and homophilic binding of rLARFN5C. A, Left, His-tagged recombinant LARFN5C (rLARFN5C) protein was eluted from metal affinity resin and applied to a 4-12\% gradient polyacrylamide gel system. Staining with GelCode Blue reagent detected an $\sim 16 \mathrm{kDa}$ protein along with a faint signal at $\sim 64 \mathrm{kDa}$. A, Right, Analysis that used the more sensitive LASE-c antibody Western blot detected signal at $\sim 16, \sim 32$, and $\sim 64 \mathrm{kDa}$. B, Left, Incubation of His-tagged rLARFN5C with enterokinase generated the predicted $\sim 11 \mathrm{kDa}$ product as detected by GelCode Blue staining. B, Right, Analysis that used the more sensitive LARFN5C $29-48$ antibody Western blots detected signal at $\sim 11, \sim 22$, and $\sim 44 \mathrm{kDa}$. $C$, Fluorescent microspheres were coated with either BSA (top two panels) or rLARFN5C (remainder of panels), sonicated for $30 \mathrm{sec}$, incubated for $1 \mathrm{hr}$ without or with the indicated antibodies, and then examined under fluorescent microscopy. BSA-coated microspheres remained dissociated, whereas rLARFN5C-coated microspheres in the absence of antibody or in the presence of preimmune antibodies underwent aggregation. LARFN5C $29-48$ or LASE-c antibodies blocked aggregation. 
staining (Fig. 3B) and was used in subsequent studies to compare bioactivity of the $\sim 16$ and $\sim 11 \mathrm{kDa}$ species. Western blot analysis of cleaved rLARFN5C that used the LARFN5C 29-48 antibody revealed bands at $\sim 11, \sim 22$, and $\sim 44 \mathrm{kDa}$ (Fig. $3 B$ ), again pointing to the possibility of the presence of LARFN5C in dimeric and tetrameric complexes. Interestingly, the $\sim 11, \sim 22$, and $\sim 44$ $\mathrm{kDa}$ banding pattern revealed by Western blot analysis of purified rLARFN5C was similar to the pattern revealed with analysis of tissue extracts.

\section{rLARFN5C induces aggregation of microspheres}

The possibility that rLARFN5C undergoes homophilic binding was tested directly with microsphere aggregation assays. Microspheres coupled with rLARFN5C demonstrated marked aggregation within $1 \mathrm{hr}$ of incubation (Fig. 3C). In contrast, BSA-coupled microspheres demonstrated no clear aggregation under the same conditions. To confirm that aggregation was specific to rLARFN5C rather than a contaminant, we added LARFN5C 2948 , LASE-c antibodies, or preimmune serum to the aggregation solution. Supporting a role for rLARFN5C itself mediating aggregation, each of these antibodies, but not preimmune serum, blocked aggregation (Fig. 3C).

Homophilic binding by rLARFN5C predicted that rLARFN5C also might bind to LAR. Protein pull-down assays with His-tagged rLARFN5C were used to determine whether rLARFN5C captures the $\sim 150$ and $\sim 110 \mathrm{kDa}$ LAR ectodomain isoforms present in neural tissues. Western blot analysis of LAR - / - E18 hippocampal extracts that used the LAR N-terminal antibody (Zhang et al., 1998) demonstrated only trace expression of the LAR $\sim 150$ and $\sim 110 \mathrm{kDa}$ isoforms (Fig. $4 A$ ). Consistent with the persistent expression of LAR $\sim 6 \mathrm{~kb}$ transcripts in $\mathrm{LAR}-/-$ mice (Yeo et al., 1997), expression of an $\sim 80 \mathrm{kDa}$ isoform was relatively unchanged. Incubation of rLARFN5C-coated metal affinity resin with LAR +/+ extracts demonstrated the capture of $\sim 150, \sim 110$, and $\sim 80 \mathrm{kDa}$ LAR isoforms (Fig. $4 \mathrm{~B}$ ). Parallel incubations performed with LAR $-/-$ extracts failed to detect capture of the $\sim 150$ and $\sim 110 \mathrm{kDa}$ proteins. The sizes of these proteins, their detection by the LAR N-terminal antibody, and their absence in LAR-deficient cells indicated that rLARFN5C bound to the LAR ectodomain. The $\sim 80 \mathrm{kDa}$ protein captured by rLARFN5C likely represents an LAR isoform with persistent expression in LAR $-/-$ neurons. Application of beads coated with the His-tagged Positope control protein resulted in the absence of pulled down proteins and confirmed that binding of the $\sim 150, \sim 110$, and $\sim 80 \mathrm{kDa}$ species was dependent on the presence of rLARFN5C.

To assess further the interaction between LARFN5C and LAR, we immunoprecipitated E16 hippocampal tissue extracts with LARFN5C N-terminal 29-48 antibody or preimmune serum, and we analyzed immune complexes by SDS-PAGE, followed by Western blotting with LAR N-terminal antibody. As shown in Figure $4 C, \sim 150$ and $\sim 110 \mathrm{kDa}$ LAR isoforms were found to coimmunoprecipitate with LARFN5C, thereby offering a second line of evidence that LARFN5C interacts with the LAR ectodomain.

\section{Expression of rLARFN5C protein by COS cells}

To verify further that the sequence encoding the novel $\mathrm{N}$ terminal of LARFN5C is translated and to determine whether LARFN5C protein could be detected in culture medium, we transfected COS cells with cDNA encoding a LARFN5C-Fc chimera with the Fc portion located at the $\mathrm{C}$ terminal. Western blot analysis that used Fc antibody detected the expected $\sim 42 \mathrm{kDa}$ LARFN5C-Fc fusion protein in both the cell pellet and culture media of LARFN5C-Fc
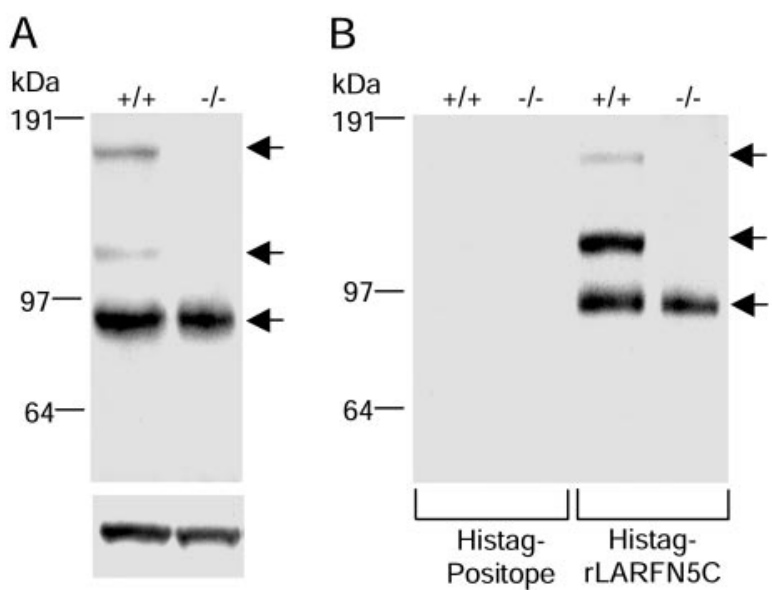

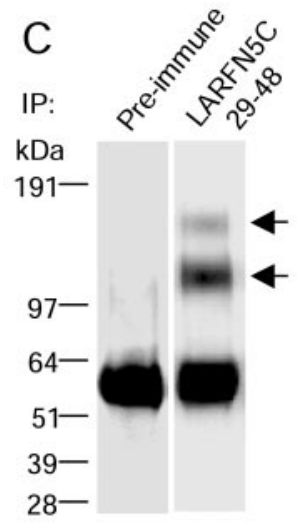

Blot: N-term LAR

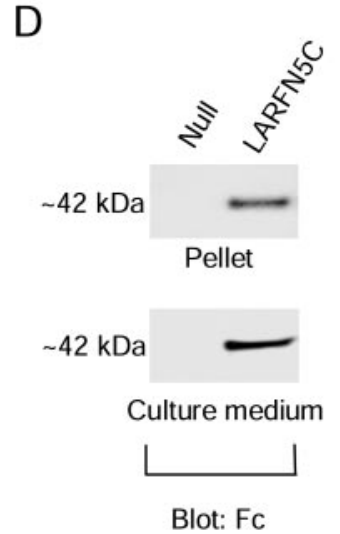

Figure 4. LAR Western blot, rLARFN5C pull-down, LARFN5C immunoprecipitation, and rLARFN5C-Fc expression assays. A, Western blot analysis that used the LAR N-terminal antibody assessed LAR protein expression in extracts prepared from E18 hippocampal cultures derived from LAR $+/+$ and $-/-$ mice. Blots were reprobed with $\beta$-actin antibody to control for differences in loading (bottom panel). In LAR - / - extracts only trace levels of the $L A R \sim 150$ $\mathrm{kDa}$ (top arrow) and $\sim 110 \mathrm{kDa}$ (middle arrow) isoforms were present, whereas similar levels of the $\sim 80 \mathrm{kDa}$ (bottom arrow) isoform were present in $L A R-/-$ and $+/+$ samples. $B$, For pull-down assays E18 hippocampal extracts were incubated with metal affinity resin coated with His-tagged rLARFN5C or His-tagged Positope control protein. After incubation the resin was washed, and bound proteins were eluted and assessed via Western blots with LAR $\mathrm{N}$-terminal antibody. Incubation of extracts with His-tagged Positope failed to pull down protein detected by the LAR antibody (lanes 1, 2). Incubation of LAR $+/+$ extracts with Histagged rLARFN5C resulted in the capture of $\sim 150 \mathrm{kDa}$ (top arrow), $\sim 110 \mathrm{kDa}$ (middle arrow), and $\sim 80 \mathrm{kDa}$ (bottom arrow) proteins detected by LAR antibody (lane 3). Incubation with LAR $-/-$ extract failed to detect the $\sim 150$ and $\sim 110 \mathrm{kDa}$ isoforms (lane 4 ), consistent with their relative absence in LAR - / - tissue. C, E16 hippocampus lysates were immunoprecipitated with preimmune or LARFN5C 29-48 antibody, and immune complexes were analyzed by Western blotting with the use of LAR N terminus monoclonal antibody. LAR $\sim 150 \mathrm{kDa}$ (top arrow) and $\sim 110 \mathrm{kDa}$ (bottom arrow) isoforms were found to coimmunoprecipitate with LARFN5C, but not with preimmune antibody. The bottom band at $\sim 55 \mathrm{kDa}$ is consistent with nonspecific lgG binding. D, $\operatorname{COS}$ cells were transfected with $p C D N A 3.1$ vector in the null form or containing the LARFN5C-Fc insert. Western blot analysis of cell pellet extract and culture medium collected at $48 \mathrm{hr}$, which used Fc fragment-specific antibody, detected the expected $\sim 42$ kDa LARFN5C-Fc fusion protein.

cDNA-transfected cells, but not in fractions of cells that were transfected with the null vector (Fig. 4D).

\section{rLARFN5C binding to COS cells is dependent on LAR expression}

To determine whether LARFN5C binds to LAR in the physiological context of cell surface binding, we compared LARFN5C binding to COS cells by using LAR- and null-transfected COS 


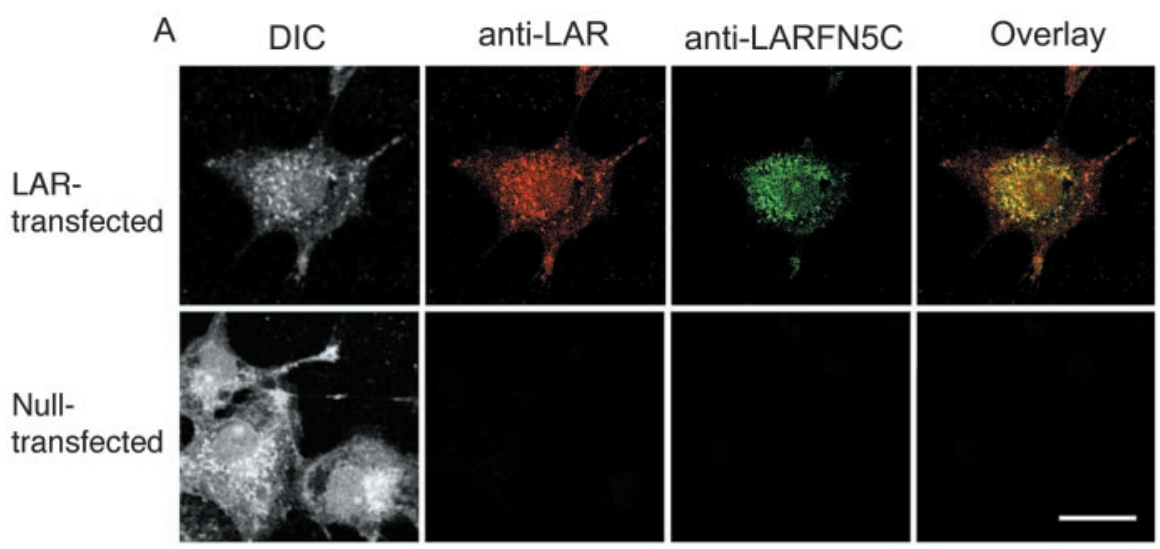

B

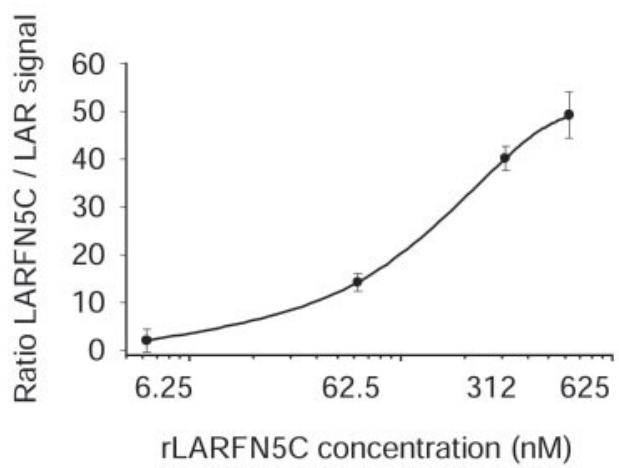

Figure 5. LAR is required for rLARFN5C binding to $\operatorname{COS}$ cells. $A, \operatorname{COS} 7$ cells were transfected with LAR (top row) or with null vector (bottom row). After transfection the cells were incubated with rLARFN5C recombinant protein (625 nm) followed by washes, immunostaining for LAR and LARFN5C, and confocal imaging. Column one shows COS cell morphology under differential interference contrast (DIC), columns two and three demonstrate imaging for LAR by using Cy3 (red) and for LARFN5C by using Alexa 488 (green), and column four shows image overlay. LARFN5C binding is entirely dependent on LAR expression; LARFN5C signal is colocalized mainly with LAR (yellow), whereas a portion of LAR signal (red) remains independent of LARFN5C. Scale bar, $10 \mu \mathrm{m} . B$, LARFN5C and LAR signal were measured for individual cells, and ratios were calculated over the indicated concentrations of rLARFN5C (mean $\pm \mathrm{SE} ; n=75)$.

cells. Previous studies demonstrated that LAR expression is absent or undetectable in COS cells (Weng et al., 1998). Immunostaining with the LAR N-terminal antibody verified that LAR was expressed by LAR-transfected COS cells and that null-transfected cells demonstrated no LAR expression (Fig. 5A). After the addition of rLARFN5C to cultures, LARFN5C 29-48 antibody demonstrated the binding of rLARFN5C to LAR-expressing cells, but no binding to null cells. Overlay of LAR and LARFN5C signal revealed that most of the rLARFN5C signal was associated with LAR signal. The relative levels of rLARFN5C binding to LARexpressing cells exhibited saturable kinetics over a low-to-mid nanomolar range with an $\mathrm{EC}_{50}$ of 100-200 nM (Fig. 5B). These findings offered a third line of evidence that LARFN5C binds to LAR. In addition, these studies demonstrated that LARFN5C binding is not a result of nonspecific protein adhesiveness but that LARFN5C binds to LAR in a manner consistent with ligandreceptor interaction.

rLARFN5C binding to E18 hippocampal neurons is correlated with LAR expression

The E18 hippocampal culture model, consisting primarily of pyramidal neurons, is a well established system for studies of neurite outgrowth (Goslin et al., 1998; Esch et al., 1999), and LAR has been shown to be expressed by pyramidal neurons in vivo (Longo et al., 1993; Zhang et al., 1998). Immunostaining with the LAR $\mathrm{N}$-terminal antibody detected abundant signal associated with
LAR $+/+$ neurons (Fig. $6 A$ ). To compare binding of exogenously added rLARFN5C with neurons with high versus low levels of LAR expression under identical conditions, we prepared mixed E18 cultures derived from LAR +/ + (high LAR-expressing) and $-/-$ (low LAR-expressing) mice. LAR immunostaining readily detected entirely distinct populations of high LAR-expressing and low LAR-expressing neurons, with an average approximately fivefold greater LAR signal in high-expressing neurons (Fig. $6 A, B, D)$. Consistent with Western blot analyses of LAR +/+ and - / - hippocampal tissue, staining with LARFN5C 29-48 antibody demonstrated similar levels of endogenous LARFN5C signal associated with high LAR-expressing and low LARexpressing neurons (Fig. 6A,D). Overlay of LAR and LARFN5C signal indicated that LARFN5C was associated primarily with LAR signal in somal, neurite, and growth cone regions. Omission of primary and secondary antibodies resulted in an absence of signal (data not shown). The addition of rLARFN5C to culture medium followed by cell washes resulted in an approximately fivefold higher LARFN5C signal associated with LAR high-expressing neurons as compared with that found with LAR low-expressing neurons (Fig. 6C,E). These findings paralleled those derived from COS cell studies and were consistent with a model in which LARFN5C binds to E18 hippocampal neurons, in part or possibly entirely, via a LAR-dependent mechanism.

rLARFN5C promotes substratum attachment and neurite outgrowth of E18 hippocampal neurons

The finding that rLARFN5C binds to LAR raised the possibility that substratum-bound rLARFN5C might mediate E18 cell adhesion and neurite outgrowth. Cell adhesion and neurite outgrowth assays were conducted by applying E18 hippocampal neurons to nitrocellulose surfaces coated with BSA, laminin, fibronectin, or rLARFN5C (Fig. 7A-E). After $2 \mathrm{hr}$ the number of neurons attached in rLARFN5C-coated wells was 10-fold higher than that promoted by BSA and at an intermediate level between that promoted by laminin and fibronectin. Immunoprecipitation of rLARFN5C solutions with either His tag or LASE-c antibodies eliminated cell adhesion activity (Fig. 7A), indicating that the rLARFN5C protein, rather than a contaminant, contained this activity.

Using the same nitrocellulose-based assays, we assessed the effect of rLARFN5C on E18 hippocampal neuron neurite outgrowth. Morphological analysis demonstrated that the majority of neurons cultured on rLARFN5C-coated nitrocellulose bore one long primary process and one or more much shorter processes (Fig. $7 A-D$ ). This pattern was consistent with previous analyses of cultured pyramidal neurons in which one long process characteristic of an axon is formed along with shorter processes characteristic of dendrites (Goslin et al., 1998). In contrast, neurons cultured on laminin generally were associated with one 
long process, consistent with previous observations showing that laminin preferentially promotes axonal growth (Esch et al., 1999). rLARFN5C-promoted processes exhibited multiple deflections characteristic of pyramidal cultures (Goslin et al., 1998), whereas laminin-promoted processes appeared longer and straighter. Neurite outgrowth patterns observed by using fluorescent GAP-43 antibody imaging were similar to those seen by using light microscopy (data not shown).

Quantitative analysis of the lengths of the longest process of each neuron revealed that the mean process length promoted by rLARFN5C was intermediate between those of laminin and fibronectin (Fig. $7 F, G$ ). Pretreatment of rLARFN5C by LASE-c and His tag antibody immunoprecipitation substantially reduced neurite-promoting activity, confirming that the rLARFN5C protein, rather than a contaminant, contained the neurite-promoting activity.

To characterize further the neuritepromoting function of rLARFN5C, we performed dose-response studies. rLARFN5C and its $\sim 11 \mathrm{kDa}$ enterokinase cleavage product promoted neurite outgrowth over a similar low picomolar dose range (Fig. $7 H)$. This finding indicated that the vectorbased His tag and leader sequence did not augment or diminish neurite-promoting activity. Administration of rLARFN5C in solution resulted in no neurite-promoting effect (data not shown). The possibility that substratum-bound rLARFN5C promotes neurite outgrowth via specific interaction with LAR and possibly other receptors predicted that the addition of rLARFN5C in solution would compete with substratum-bound LARFN5C receptor binding and thereby inhibit its neuritepromoting activity. Over a concentration range of $\sim 10-100 \mathrm{nM}$, rLARFN5C inhibited the neurite-promoting effect of substratum-

bound rLARFN5C by 30\% (Fig. 7I). It was of particular interest to note that this inhibitory effect occurred at similar concentrations in which rLARFN5C demonstrated dose-dependent binding to LAR expressed by COS cells. This competitive inhibitory effect provided further evidence that rLARFN5C functions via receptor-type interactions rather than via nonspecific adhesive mechanisms. The absence of further inhibition at higher concentrations suggested that rLARFN5C in solution did not function as a simple antagonist. Other possibilities included functioning as a partial antagonist or promoting neurite outgrowth via non-LAR receptors in the higher concentration range.

\section{Dependence of rLARFN5C promotion of neurite outgrowth} on the presence of neuronal LAR

The findings that rLARFN5C undergoes homophilic binding, binds to the ectodomain of LAR, promotes neurite outgrowth of LAR-expressing E18 neurons, and demonstrates competitive properties are consistent with a model in which its neurite- promoting activity is mediated, in part, via interaction with neuronal LAR. The role for LAR in mediating rLARFN5C activity was tested directly by conducting dose-response studies with E18 hippocampal neurons derived from LAR $+/+$ and $-/-$ mice. The potency of laminin in promoting neurite outgrowth of LAR $+/+$ and $-/-$ neurons was equivalent, indicating the absence of a nonspecific impairment of neurite outgrowth in LAR - / - neurons (Fig. $8 \mathrm{~A}$ ). In contrast to laminin, rLARFN5C demonstrated an approximately fivefold loss in potency when applied to LAR $-/-$ neurons (Fig. 8 B). It was of particular interest to note that this degree of loss in potency was similar to the fivefold loss in binding of rLARFN5C to LAR $-/-$ neurons (Fig. $6 E$ ). These findings further supported the hypothesis that rLARFN5C promotes neurite outgrowth in part (or possibly entirely) via homophilic interaction with neuronal LAR. The persistence of rLARFN5C-induced neurite outgrowth in LAR -/- neurons was likely to have resulted either from persisting LAR expression or, alternatively, via heterophilic mechanisms. 

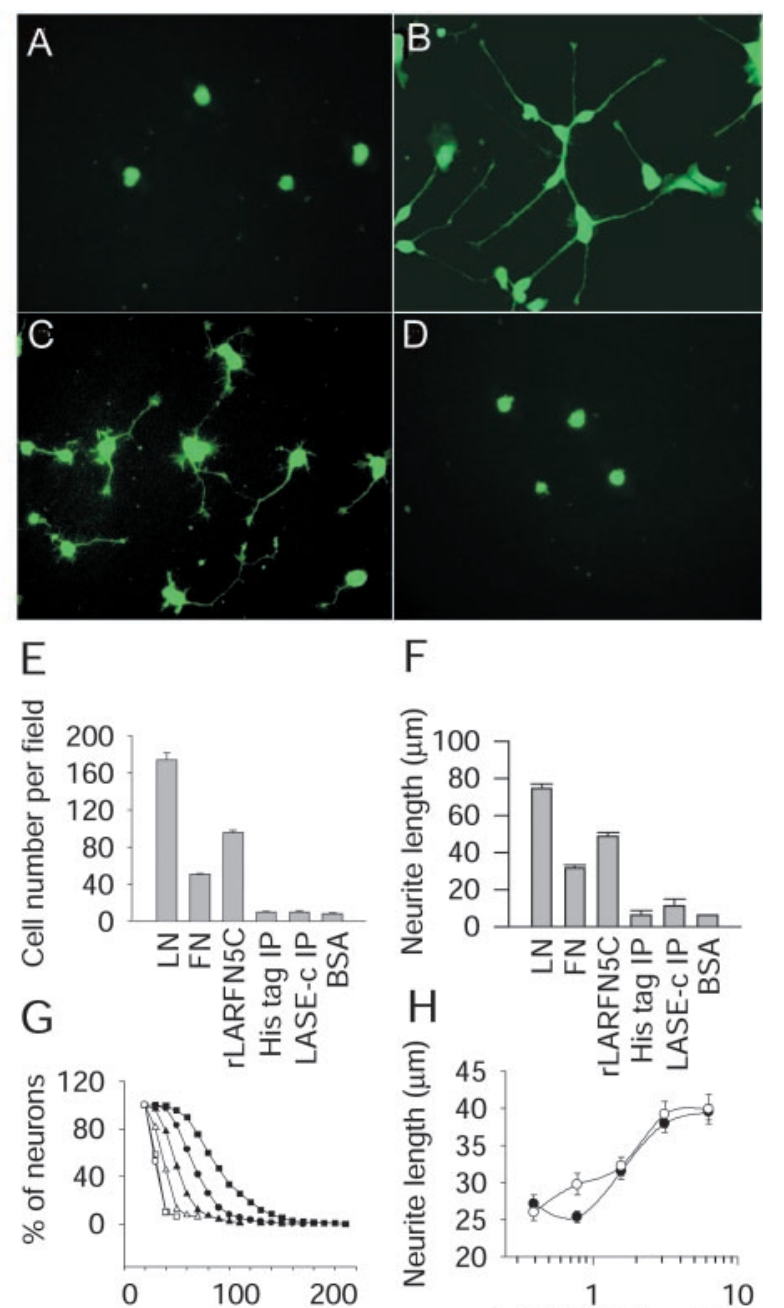

Neurite length $(\mu \mathrm{m})$

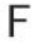

$\mathrm{F}$
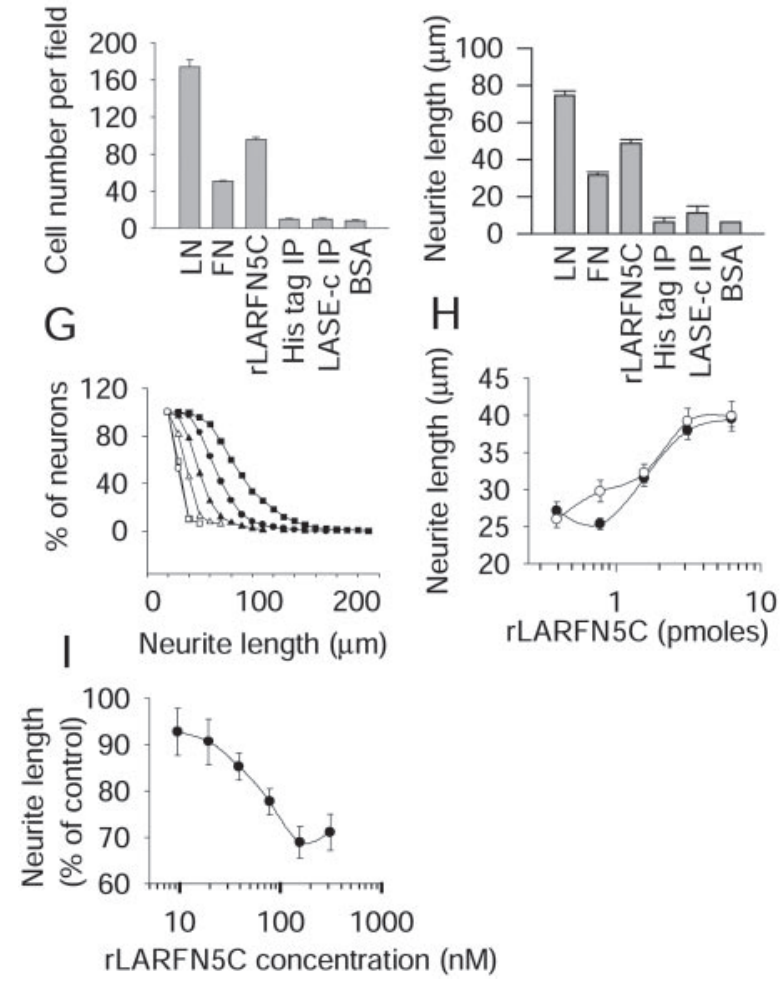

Figure 7. Characterization of rLARFN5C neurite-promoting activity. E18 hippocampal neurons were cultured for $24 \mathrm{hr}$ on nitrocellulose coated with BSA $(A)$, laminin $(B)$, $\operatorname{rLARFN5C}(C)$, or rLARFN5C (D) subjected to His tag immunoprecipitation. After fixation the neurons were immunostained with GAP-43 antibody, followed by Alexa 488 green-conjugated goat antirabbit lgG. E, E18 hippocampal neurons were plated on nitrocellulose coated with the indicated proteins (LN, laminin; FN, fibronectin). rLARFN5C was added to substrate either directly (rLARFN5C) or after pretreatment via immunoprecipitation (IP) with His tag or LASE-c antibody. BSA was included as an additional negative control. After $2 \mathrm{hr}$ of incubation the cells were washed and fixed. The mean number of cells $( \pm S E)$ present per field is shown. For laminin, fibronectin, and rLARFN $5 C \sim 200-300$ fields over a series of six separate studies were assessed. For each of the three negative control conditions $\sim 50$ fields were assessed in total. F, E18 hippocampal neurons were plated on nitrocellulose coated with the indicated proteins. rLARFN5C was added to substrate either directly (rLARFN5C) or after pretreatment via IP with His tag or LASE-c antibody. After $24 \mathrm{hr}$ the neurite lengths were measured (mean $\pm \mathrm{SE}$ ). For laminin, fibronectin, and rLARFN5C $\sim 400-900$ neurites over a series of eight studies were measured. For each of the three negative control conditions $10-60$ neurites were measured. $G$, Cumulative distribution of neurite length measurements (BSA, open circles; His tag IP, open boxes; LASE-c IP, open triangles; FN, filled triangles; rLARFN5C, filled circles; $L N$, filled boxes). $H$, E18 hippocampal neurons were plated on nitrocellulose substrate coated with the indicated concentrations of rLARFN5C. For each dose that was tested $80-250$ neurites were measured.

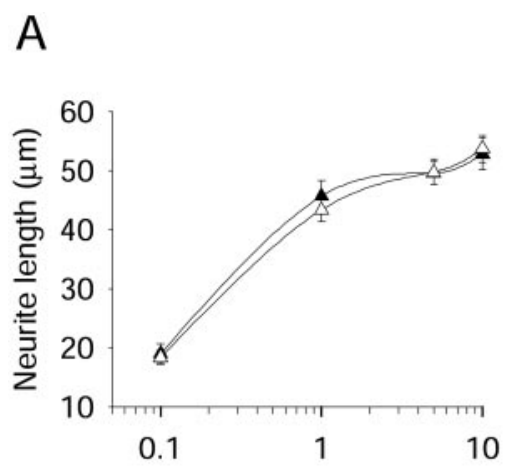

LN concentration $(\mu \mathrm{g} / \mu \mathrm{l})$

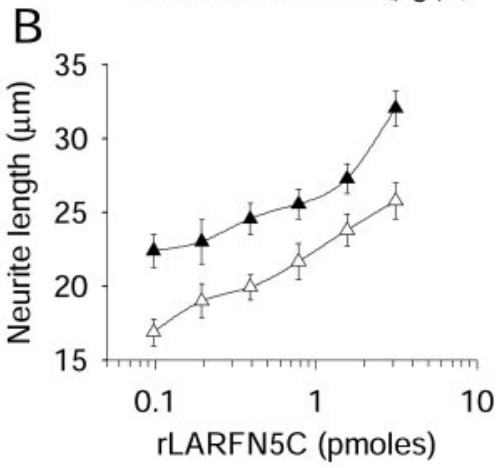

Figure 8. rLARFN5C-induced neurite outgrowth is partially dependent on the presence of neuronal LAR. A, E18 hippocampal neurons derived from LAR $+/+$ (filled triangles) and LAR $-/-$ (open triangles) mice were cultured in wells coated with laminin applied at the indicated doses. After $24 \mathrm{hr}$ the neurite lengths were determined (mean $\pm \mathrm{SE} ; 80-230$ neurites were measured for each genotype and each concentration). The potency of laminin in inducing neurite outgrowth from $L A R-I-$ neurons was unchanged. $B$, E18 hippocampal neurons derived from $L A R+1+$ and $L A R-1-$ mice were cultured in wells coated with the rLARFN5C protein applied at the indicated doses. After $24 \mathrm{hr}$ the neurite lengths were determined (mean $\pm \mathrm{SE}$; $70-220$ neurites were measured for each genotype and each concentration). rLARFN5C had a fivefold loss of potency in LAR $-/-$ cultures.

\section{Discussion}

Previously characterized LAR extracellular domain protein isoforms include the $\sim 150 \mathrm{kDa}$ isoform corresponding to the fulllength $\sim 8 \mathrm{~kb}$ LAR transcript and the $\sim 110 \mathrm{kDa}$ isoform corresponding the $\sim 7 \mathrm{~kb}$ LAR transcript, omitting FNIII domains 4,6 , and 7 (Zhang and Longo, 1995; Zhang et al., 1998). The present study identifies a novel $\sim 1.6 \mathrm{~kb}$ LAR transcript encoding an $\sim 11$ $\mathrm{kDa}$ isoform termed LARFN5C. LARFN5C contains a novel 49 residue $\mathrm{N}$ terminal followed by the nine residue LASE-c insert and the C-terminal half of the LAR FNIII-5 domain. Multiple lines of evidence indicate that LARFN5C binds via homophilic interaction to itself and to the LAR ectodomain. LARFN5C forms homodimer and homotetramer complexes, and rLARFN5C-coated microspheres demonstrate aggregation blocked by rLARFN5C antibodies. rLARFN5C pull-down assays capture LAR ectodomain isoforms, immunoprecipitation with rLARFN5C antibodies results in capture of LAR ectodomain isoforms, and rLARFN5C binding to COS cells is entirely dependent on LAR

\section{$\leftarrow$}

Mean neurite length \pm SE is shown. Filled circles indicate results with $\sim 16 \mathrm{kDa}$ uncleaved rLARFN5C, and open circles indicate results with enterokinase-cleaved $\sim 11 \mathrm{kDa}$ rLARFN5C. I, E18 hippocampal neurons were plated on nitrocellulose substrate coated with $3.125 \mathrm{pmol}$ of rLARFNSC, and soluble rLARFN5 C was added to culture medium at the indicated concentrations. For each dose that was tested $70-200$ neurites were measured. Mean neurite length $\pm S E$ is shown. 
expression. Three lines of evidence support a model in which LARFN5C binds to E18 neurons and promotes neurite outgrowth, in part, via homophilic interaction with LAR. First, rLARFN5C binding to E18 neurons is decreased in LAR-deficient neurons. Second, soluble rLARFN5C inhibits the neuritepromoting effects of substrate-bound rLARFN5C at concentrations similar to those at which it binds to LAR. Third, the potency of rLARFN5C in promoting neurite outgrowth decreases by fivefold when applied to LAR $-/-$ neurons. These studies are the first to report a LAR isoform that demonstrates homophilic interaction and that promotes neurite outgrowth.

The present findings point to the C-terminal half of the LAR FNIII-5 domain as a candidate region important for binding by LARFN5C and perhaps other LAR ligands. LARFN5C-toLARFN5C homophilic binding is likely to result from one of the following three potential binding interactions: $\mathrm{N}$-terminal to $\mathrm{N}$-terminal isologous homophilic binding, C-terminal FNIII-5 to C-terminal FNIII-5 isologous homophilic binding, or C-terminal FNIII-5 to N-terminal heterologous homophilic binding. The finding that LARFN5C binds to LAR and the absence of the LARFN5C N-terminal sequence in LAR make the possibility of $\mathrm{N}$-terminal to $\mathrm{N}$-terminal isologous homophilic binding unlikely. For either of the other binding scenarios, the $\mathrm{C}$ terminal of the LAR FNIII-5 domain within full-length LAR is likely to serve as the binding target. In the overall context of $\sim 150$ $\mathrm{kDa}$ LAR-type PTP ectodomains, identification of this $\sim 6 \mathrm{kDa}$ segment as one candidate region modulating LAR-mediated neurite outgrowth represents an almost 25 -fold narrowing in size of a core LAR-type segment mediating neurite outgrowth. Clearly, these findings do not rule out the presence of other LAR subdomains modulating neurite outgrowth. In current studies in our laboratory, synthetic peptides corresponding to the C-terminal FNIII region of LARFN5C, but not those corresponding to the novel $\mathrm{N}$ terminal, demonstrate homophilic binding. These findings point further to this domain as a key mediator of homophilic binding and raise the possibility that LAR isoforms lacking the LASE-e encoded N-terminal sequence also might demonstrate homophilic binding.

A key mechanistic issue in PTP receptor function is whether homophilic binding plays a role in PTP receptor regulation of neurite outgrowth. The full-length ectodomain of the $140 \mathrm{kDa}$ PTP $\delta$ receptor promotes neurite outgrowth and binds to a 140 $\mathrm{kDa}$ neural protein, raising the strong possibility of homophilic binding. Alternatively, heterophilic interaction via similarly sized receptors remains possible (Wang and Bixby, 1999). РTP $\mu$ and РТР $\kappa$ full-length ectodomains undergo homophilic binding and stimulate neurite outgrowth (Brady-Kalnay and Tonks, 1994; Sap et al., 1994; Zondag et al., 1995; Burden-Gulley and BradyKalnay, 1999; Drosopoulos et al., 1999). The determination of whether these ectodomain neurite-promoting effects are mediated via homophilic or heterophilic binding will benefit from the application of РTP $\delta$-, РТP $\mu$-, and РTP $\kappa$-deficient neurons. In the case of LAR and LARFN5C the availability of LAR-deficient neurons, along with the findings in the present study, supports a model in which promotion of neurite outgrowth by LAR and possibly other LAR-type PTPs is mediated, at least in part, via homophilic interaction.

Elucidation of functional roles of PTP ectodomains raises the question of how the potency of rLARFN5C neurite-promoting compares with that of other recombinant PTP ectodomains. Given that the available data are limited to in vitro studies, differences in modes of protein application, the use of artificial substrates, differences in orientation of bound proteins, and differ- ences in the types of neurons tested clearly limit comparisons of "potencies." For PTP $\kappa$ studies, recombinant protein was present in solution at $10 \mu \mathrm{g} / \mathrm{ml}(\sim 70 \mathrm{nM})$ in cultures of cerebellar granule neurons (Drosopoulos et al., 1999). In PTP $\mu$ neurite-promoting assays aliquots of $2-4 \mu \mathrm{g}(\sim 10,000-20,000$ pmol; assayed with retinal neurons) (Burden-Gulley and Brady-Kalnay, 1999) and in PTP $\delta$ studies aliquots of $0.012-0.100 \mu \mathrm{g}(\sim 80-700 \mathrm{pmol}$; assayed with forebrain neurons) (Wang and Bixby, 1999) were applied to similar areas of nitrocellulose substrates. In the present studies rLARFN5C aliquots of $\sim 0.4-7.0 \mathrm{pmol}$, a quantity 100 - to 1000 -fold less than the applications of $\operatorname{PTP} \mu$ and $\mathrm{PTP} \delta$, were sufficient for eliciting neurite outgrowth. Clearly, the actual relative potencies of LAR-type PTP ectodomains will be assessed more accurately in physiological contexts. Although formal receptor-binding studies are beyond the scope of the present work, the ability of soluble rLARFN5C to bind to COS cell LAR over a two-log dose range of 6-600 nM and to inhibit substratum-bound rLARFN5C at similarly low nanomolar concentrations places LARFN5C at the lower end of concentration ranges typical of FNIII or Ig cell domains promoting cell adhesion or neurite outgrowth.

The unusual finding that a retained intron within a receptor leads to the production of a small ectodomain protein isoform that can function as a ligand for the same receptor to promote neurite outgrowth is of particular interest and raises the possibility of potential endogenous functional roles of LARFN5C. Formal secretion studies will be required to determine whether the LARFN5C N-terminal sequence is capable of mediating secretion via conventional mechanisms, or, if not, whether LARFN5C secretion occurs via a nonclassical pathway. Selective elimination of the LARFN5C isoform or its function in vivo will be required to determine whether LARFN5C has a physiological role. Regardless of the presence or absence of an endogenous physiological function, identification of LARFN5C and its ability to bind LAR and promote neurite outgrowth constitutes the first demonstration of a functional subdomain within a PTP receptor ectodomain and provides a novel basis for creating small molecule LARbased ligands for the purpose of positively or negatively modulating neurite outgrowth. The identification of LARFN5C also might provide a useful tool for identifying endogenous LAR ligands, for elucidating LAR domains involved in their binding, and for potentially modulating effects of endogenous ligands.

\section{References}

Baker MW, Macagno ER (2000) The role of a LAR-like receptor tyrosine phosphatase in growth cone collapse and mutual-avoidance by sibling processes. J Neurobiol 44:194-203.

Baker MW, Rauth SJ, Macagno ER (2000) Possible role of the receptor protein tyrosine phosphatase HmLAR2 in interbranch repulsion in a leech embryonic cell. J Neurobiol 45:47-60.

Bashaw GJ, Kidd T, Murray D, Pawson T, Goodman CS (2000) Repulsive axon guidance: Abelson and Enabled play opposing roles downstream of the roundabout receptor. Cell 101:703-715.

Bixby JL (2000) Receptor tyrosine phosphatases in axon growth and guidance. NeuroReport 14:R5-R10.

Brady-Kalnay SM, Tonks NK (1994) Identification of the homophilic binding site of the receptor protein tyrosine phosphatase PTP $\mu$. J Biol Chem 269:28472-28477.

Burden-Gulley SM, Brady-Kalnay SM (1999) РTP $\mu$ regulates N-cadherindependent neurite outgrowth. J Cell Biol 144:1323-1336.

Chisholm A, Tessier-Lavigne M (1999) Conservation of axon guidance mechanisms. Curr Opin Neurobiol 9:603-615.

Clandinin TR, Lee CH, Herman T, Lee RC, Yang AY, Ovasapya S, Zipursky SL (2001) Drosophila LAR regulates R1-R6 and R7 target specificity in the visual system. Neuron 32:237-248. 
den Hertog J (1999) Protein tyrosine phosphatases in development. Mech Dev 85:3-14.

Desai CJ, Krueger NX, Saito H, Zinn K (1997) Competition and cooperation among receptor tyrosine phosphatases control motor neuron growth cone guidance in Drosophila. Development 124:1941-1952.

Drosopoulos NE, Walsh FS, Doherty P (1999) A soluble version of the receptor-like protein tyrosine phosphatase $\kappa$ stimulates neurite outgrowth via a Grb2/MEK1-dependent signaling cascade. Mol Cell Neurosci 13:441-449.

Esch T, Lemmon V, Banker G (1999) Local presentation of substrate molecules directs axon specification by cultured hippocampal neurons. J Neurosci 19:6417-6426.

Gershon TR, Baker MW, Nitabach M, Macagno ER (1998) The leech receptor protein tyrosine phosphatase HmLAR2 is concentrated in growth cones and is involved in process outgrowth. Development 125:1183-1190.

Goslin K, Asmussen H, Banker G (1998) Rat hippocampal neurons in low density culture. In: Culturing nerve cells (Banker G, Goslin K, eds), pp339-370. Cambridge, MA: MIT.

Kaufmann N, DeProto J, Ranjan R, Wan H, Van Vactor D (2002) Drosophila liprin- $\alpha$ and receptor phosphatase Dlar control synapse morphogenesis. Neuron 34:27-38.

Krueger NX, Van Vactor D, Wan HI, Gelbart WM, Goodman CS, Saito H (1996) The transmembrane tyrosine phosphatase DLAR controls motor axon guidance in Drosophila. Cell 84:611-622.

Lanier LM, Gertler FB (2000) From Abl to actin: Abl tyrosine kinase and associated proteins in growth cone motility. Curr Opin Neurobiol 10:80-87.

Longo FM, Martignetti JA, Le Beau JM, Zhang JS, Barnes JP, Brosius J (1993) Leukocyte common antigen-related receptor-linked tyrosine phosphatase. Regulation of mRNA expression. J Biol Chem 268:26503-26511.

Maurel-Zaffran C, Suzuki T, Gahmon G, Treisman GE, Dickson BJ (2001) Cell-autonomous and -nonautonomous functions of LAR in R7 photoreceptor axon targeting. Neuron 32:225-235.

Nielsen H, Engelbrecht J, Brunak S, von Heijne G (1997) Identification of prokaryotic and eukaryotic signal peptides and prediction of their cleavage sites. Protein Eng 10:1-6.

Petrone A, Sap J (2000) Emerging issues in receptor protein tyrosine phosphatase function: lifting fog or simply shifting? J Cell Sci 113:2345-2354.

Sap J, Jiang YP, Friedlander D, Grumet M, Schlessinger J (1994) Receptor tyrosine phosphatase R-PTP- $\kappa$ mediates homophilic binding. Mol Cell Biol 14:1-9.

Schaapveld RQ, Schepens JT, Bachner D, Attema J, Wieringa B, Jap PH, Hendricks WJ (1998) Developmental expression of the cell adhesion molecule-like protein tyrosine phosphatase LAR, RPTP $\delta$ and RPTP $\sigma$ in the mouse. Mech Dev 77:59-62.

Skarnes WC, Moss JE, Hurtley SM, Beddington RS (1995) Capturing genes encoding membrane and secreted proteins important for mouse development. Proc Natl Acad Sci USA 92:6592-6596.

Stoker A (2001) Receptor tyrosine phosphatases in axonal growth and guidance. Curr Opin Neurobiol 11:95-102.

Van Lieshout EM, Van der Heijden I, Hendriks WJ, Van der Zee CE (2001) A decrease in size and number of basal forebrain cholinergic neurons is paralleled by diminished hippocampal cholinergic innervation in mice lacking leukocyte common antigen-related protein tyrosine phosphatase activity. Neuroscience 102:833-841.

Van Vactor D (1998) Protein tyrosine phosphatases in the developing nervous system. Curr Opin Cell Biol 10:174-181.

Wang J, Bixby JL (1999) Receptor tyrosine phosphatase- $\delta$ is a homophilic, neurite-promoting cell adhesion molecule for CNS neurons. Mol Cell Neurosci 14:370-384.

Weng LP, Yuan J, Yu Q (1998) Overexpression of the transmembrane tyrosine phosphatase LAR activates the caspase pathway and induces apoptosis. Curr Biol 8:247-256.

Wills Z, Bateman J, Korey CA, Comer A, Van Vactor D (1999) The tyrosine kinase Abl and its substrate Enabled collaborate with the receptor phosphatase Dlar to control motor axon guidance. Neuron 22:301-312.

Xie YM, Yeo TT, Zhang C, Yang T, Tisi MT, Massa SM, Longo FM (2001) The leukocyte common antigen-related protein tyrosine phosphatase receptor regulates regenerative neurite outgrowth in vivo. J Neurosci 21:5130-5138.

Yeo TT, Yang T, Massa SM, Zhang JS, Honkaniemi J, Butcher LL, Longo FM (1997) Deficient LAR expression decreases basal forebrain cholinergic neuronal size and hippocampal cholinergic innervation. J Neurosci Res $47: 348-360$.

Zhang JS, Longo FM (1995) LAR tyrosine phosphatase receptor: alternative splicing is preferential to the nervous system, coordinated with cell growth, and generates novel isoforms containing extensive CAG repeats. J Cell Biol 128:415-431.

Zhang JS, Honkaniemi J, Yang T, Longo FM (1998) LAR tyrosine phosphatase receptor: a developmental isoform is present in neurites and growth cones and its expression is regional- and cell-specific. Mol Cell Neurosci 10:271-286.

Zondag GC, Koningstein GM, Jiang YP, Sap J, Moolenaar WH, Gebbink MF (1995) Homophilic interactions mediated by receptor tyrosine phosphatases mu and kappa. A critical role for the novel extracellular MAM domain. J Biol Chem 270:14247-14250. 